\title{
PSIHOLOGIJA BOJA: RAZISKAVA VOJAKOVEGA DOŽIVLJANJA VOJNE IN PSIHIČNIH POSLEDIC, KI JIH POVZROČA BOJEVANJE
}

\section{PSYCHOLOGY OF COMBAT: RESEARCH ON A SOLDIER'S EXPERIENCING OF WAR AND PSYCHOLOGICAL CONSEQUENCES OF COMBAT}

Povzetek Delovanje človeka v boju, njegovo doživljanje vojne in nasilja so teme, ki niso pogoste v znanstveni literaturi. Med avtorji, ki so ta vidik predstavili še najbolj nazorno, so S. L. A. Marshall (1947), Richard Holmes (1985) in David Grossman (2004, 2009). Avtor je podobno raziskavo izvajal tudi sam. Izvajal je intervjuje z veterani preteklih vojn, pri čemer je ugotavljal, kako so jo doživljali in kakšne psihične posledice pušča delovanje v ekstremnih razmerah. V prispevku so predstavljeni rezultati študije in primerjava rezultatov avtorja s spoznanji omenjenih tujih avtorjev. Avtor ugotavlja, da so velike podobnosti med doživljanji angloameriških vojakov in vzhodnoevropskim ter balkanskih vzorcem, ki jih je zajel v raziskavo. To ga navaja na misel, da je odziv človeka na nevarnost univerzalen, vsaj v okviru zahodne kulture in sedanjega časa.

Ključne besede

Abstract A person's functioning in combat and how they experience war and violence are the topics not frequently addressed in scientific literature. S. L. A. Marshall (1947), Richard Holmes (1985) in David Grossman $(2004,2009)$ are the authors who have presented this perspective in the most illustrative way so far. The author has conducted a similar research himself. He has conducted interviews with the veterans of the past wars trying to establish how they experienced the war and what psychological consequences operations in extreme conditions leave on people. The article presents the results of this study and a comparison of the author's results with the results obtained by the above-mentioned authors. The author notes great similarity between the experiences of the Anglo-American soldiers and Eastern-European and Balkan patterns he included in the research. This provokes the author's idea of the universality of human response to danger, at least within the Western culture and the modern era.

Key words Psychology of combat, war, combat stress, sociology of war. 
Uvod Avtorjev, ki bi predstavljali resničen obraz vojne, ni veliko. Najodmevnejša dela so, vsaj v novejšem času, napisali že omenjeni ameriški uradni vojaški zgodovinar S. L. A. Marshall, nekdanji predavatelj na britanski vojaški akademiji Sandhurst Richard Holmes, in prav tako nekdanji predavatelj na ameriški vojaški akademiji West Point, David Grossman. Njihova dela so posledica intervjujev, ki so jih izvajali z veterani in, v primeru Grossmana, tudi pripadniki policijskih sil. Vsi trije se strinjajo, da so vojske večinoma namenjene bojevanju, da vojna ni nič drugega kot spopad sil, pri čemer poskuša vsaka stran čim bolj temeljito izničiti drugo, in da je končni cilj vojsk to dejavnost čim učinkoviteje izvajati.

Marshall, veteran prve svetovne vojne, je drugo svetovno vojno preživel med bojnimi enotami, do leta 1943 na pacifiškem, zadnji leti pa na evropskem bojišču. Takoj po koncu vojne je generalštab ZDA zahteval, da zbere izkušnje, ki so jih taktične enote prejele med boji. Opravil je gigantsko delo - razgovore s štiristo četami, ki so bile udeležene $\mathrm{v}$ neposrednih spopadih na obeh straneh zemeljske oble. Za njegovimi razkritji, opisanimi v knjigi Man against fire (1947), so neposredna pričevanja več tisoč vojakov, podčastnikov in častnikov. Njegova spoznanja so bila res prelomna. Opisuje, da je vojna kaos, v katerem je napovedovanje delovanja vojaka zelo težko. Odpovedovali so ljudje, ki so pred vojno kazali trdnost in pogum, medtem ko so pritiske zdržali vojaki, ki so bili na urjenjih neopazni. Trdi, da v boju na daljši rok hladnokrvno deluje le četrtina vojakov, medtem ko se preostali nevarnostim in streljanju na nasprotnika raje izognejo. Pod pritiski boja najbolje delujejo enote $\mathrm{z}$ dobro moralo in kohezijo, enote, ki so odločno in dobro vodene, pa še zanje ni nujno, da ne bodo popustile:

»Ni vojaka, ki bi bil neustrašen in v vseh pogojih bojevanja, in ni čete, ki bi bila stalno dobra ali neodporna na šok. So le čete, ki so bolj odporne kot druge in manj podvržene razpadu ob nepričakovanih kriznih situacijah ali presenečenjih." (Marshall, str. 182)

Ob popuščanju mehanizmov, ki ščitijo enoto pred razpadom, prihaja do serije patoloških procesov, od paničnega bega, psihičnih motenj prek nediscipline do morilskih orgij.

Holmesovo delo je nadgradnja - in potrditev - Marshallovega, pri čemer je podatke dopolnil še z britanskimi izkušnjami, vse do falklandske vojne. Njegovo knjigo Acts of war (1985) odlikuje psihološka analiza vojaka in enot pred bojem, med njim in po njem. V njej med drugim odpira tudi tabuje o vojakovem strahu pred poškodbami in smrtjo, o agoniji umiranja, vojnih zločinih, umazanosti in ničvrednosti življenja vojaka na bojišču. Omenjeni avtor trdi, da je vojak kot baterija, ki se z vsakim bojem bolj sprazni, dokler od njega ne ostane zgolj prazna lupina. Ta mehanizem dobro povzema izjava vojaka D. J. B. Houchina:

"S časom je postajalo čedalje težje, čedalje bolj je nažiralo mojo samokontrolo in odločnost. Mislim, da je vzdržljivost povezana s čustveno stabilnostjo, umsko 
kapaciteto in seveda karakterjem. Postal sem utrujen že samo ob misli, da bo treba iti skozi to še enkrat ... Ob vsaki akciji se zgubi del človekove kontrole in ljudje začenjajo iskati izgovore, da se izognejo tej neprijetnosti ... Preveč sem se bojeval in morali bi me premestiti v poveljstvo. Spremenil sem se v razvalino." (Holmes 1989, str. 217)

Pri trditvi, da vojna vojake psihično uničuje, je bil drzen, vendar še vseeno manj kot Grossman, bivši ranger in padalec, ki je v svojih knjigah On killing (2009) in On combat (2004) to trditev predstavil kot dejstvo in v njih razvil teorijo, kako človeka pripraviti na ubijanje in s kakšnimi posledicami se bo srečeval pri tem.

V knjigi On killing (2009) je predstavil svoj pogled na psihologijo ubijanja. Trdi, da ima uboj svoje zakonitosti in poteka v več fazah, od strahu pred ubojem prek vzhičenosti takoj po njem do racionalizacije, ko vojak uboj osmisli in opraviči (slika 1). Pričakovano in najbolj običajno je, da gre vojak skozi vse faze in se na ubijanje navadi. Težava nastane, če se zaustavi na kateri koli od omenjenih faz in je ni sposoben prerasti. Takrat zdrsi v psihične motnje. Grossman zatrjuje, da vojak ni pred motnjami varen niti takrat, če se na ubijanje navadi. Motnje se lahko pojavijo tudi pozneje z zamikom.

Slika 1:

Psihološki proces ubijanja po

Grossmanu.

Vir:

Grossman, 2009, str. 234.
PROCES UBIJANJA

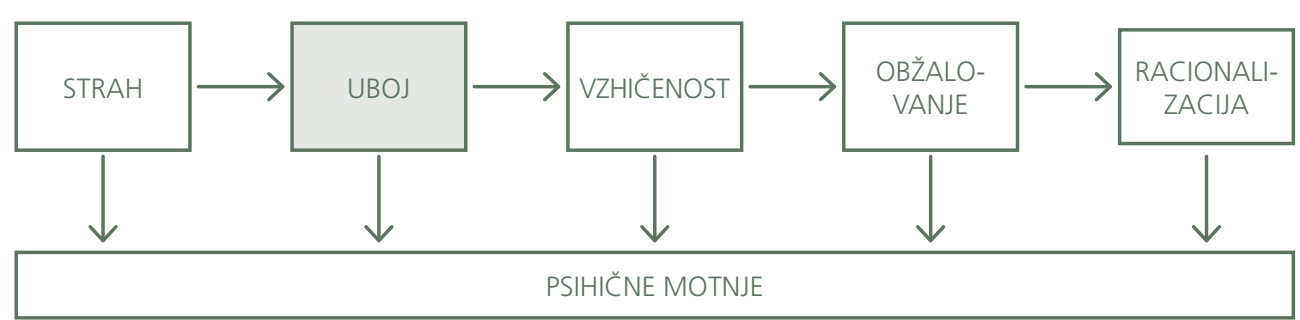

Razvil je tudi model, ki razkriva, kateri dejavniki pospešujejo uboj. Prvi je osebnost vojaka, drugi pritisk avtoritete, tretji pritisk skupine in četrti značilnosti žrtve (slika 2). Najlažje bo torej ubijal tisti, ki je agresivne narave in z malo empatije do soljudi, ki mu je uboj ukazan, pri čemer ga spodbujajo tudi sovojaki in kadar je na drugi strani nemočna žrtev, bodisi vojak bodisi civilist, zanj inferiornih nazorov.

Področje psihičnih motenj vojaka je dobro raziskano področje vojaške medicine. V ameriških vojaških priročnikih o bojnem stresu FM 8-51 (1994) in FM 4-02.5 (2006) 
Slika 2:

Grossmanov

model

dejavnikov,

ki pospešujejo

uboj.

Vir.

Prirejeno po

Grossmann

2009, str. 142.

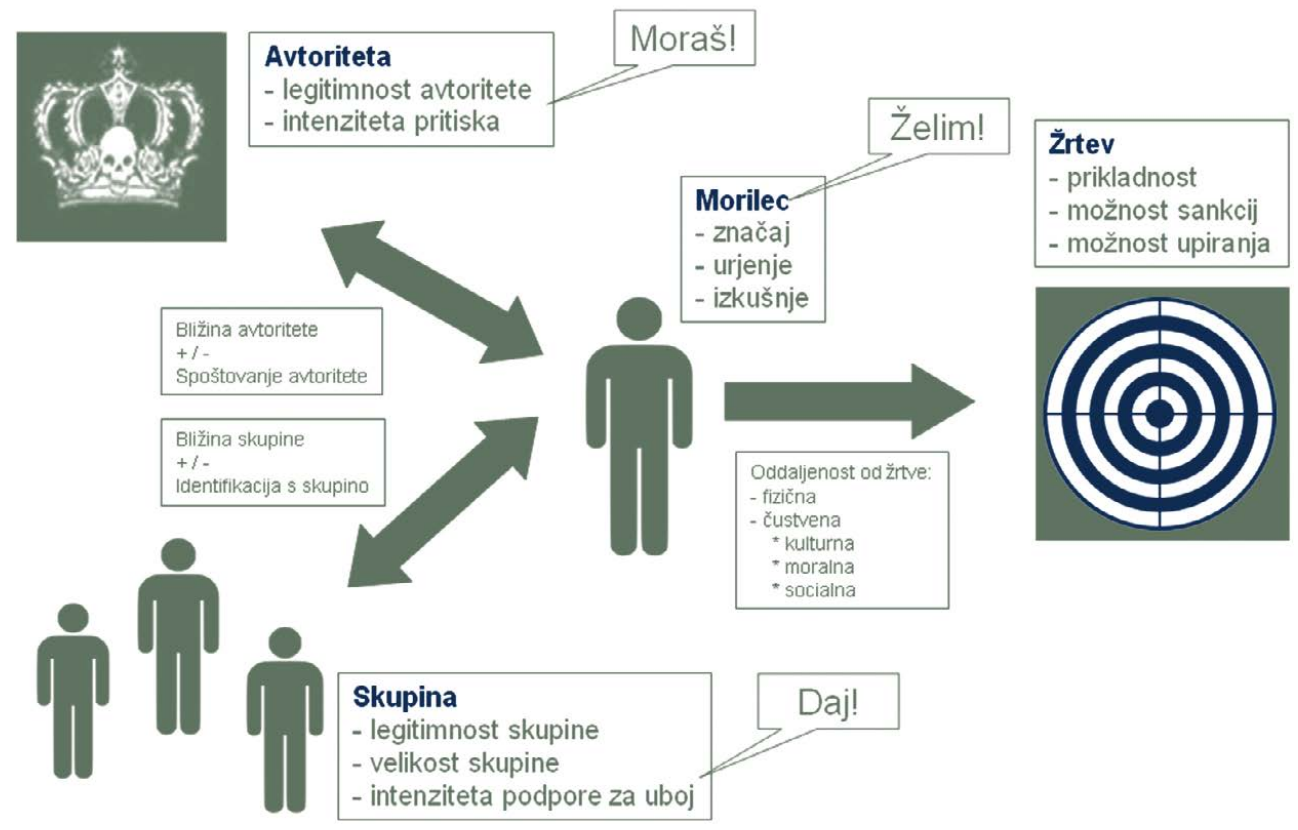

je zaslediti trditev, da izpostavljenost vojaka stresorjem lahko povzroči utrditev tako njega kot njegove enote, vendar lahko povzroči tudi razpad vojaškega vedenja ali kratkotrajno stresno bolezen. Vse tri oblike lahko ob nepravilnem pristopu preidejo $\mathrm{v}$ dolgotrajne stresne motnje v obliki posttravmatske stresne motnje (PTSM).

Vojaki s simptomi bojnega stresa kažejo zelo različne vrste vedenja, pri čemer so lahko nekatere videti precej dramatično. Večina vojakov bo v vojni kazala lažje oblike bojnega stresa. Med te simptome spadajo utrujenost, počasnost, slab spanec, razdražljivost, šibka koncentracija in pritoževanje zaradi bolezni, ki imajo pravzaprav psihični vzrok. Resnejši simptomi dajejo občutek, da je oziroma bo vojak odpovedal. Pri teh simptomih še ni nujno, da vojak ni sposoben bojnega delovanja, vendar je zelo blizu zloma.

David H. Marlowe v svojem delu Psychological and Psychosocial Consequences of Combat and Deployment with Special Emphasis on the Gulf War (2000) navaja poročilo psihiatra Spiegla, ki je leta 1943 delal z ameriškimi enotami v Tuniziji. Opazil in opisal je celoten spekter motenj:

"Simptomi psihiatričnih bolnikov so različni. Segajo od napetosti, suhih ust, tresenja, močnejšega bitja srca prek večje napetosti in preobčutljivosti za hrup 
do nekontroliranega tresenja, vpitja, joka, zmedenega tekanja naokrog in skoraj popolne izgube občutka za dogajanje, čas in prostor. Ti skrajni primeri niso pogosti. Če je bilo kaj pogosto, je bila to prisotnost utrujenosti. Utrujenost, ki ni bila samo rezultat fizične preobremenjenosti in pomanjkanja spanca, temveč tudi rezultat stalne napetosti in strahu ..."

Ameriška vojaška medicina trdi, da se pod dolgotrajnimi pritiski vsak zlomi. Riddle je v svojem članku Self-reported Combat Stress among Troops Deployed to Iraq and Afghanistan (2006) opisal stanje vojakov neke ameriške enote po petdesetih dneh nenehnih bojev v Normandiji: "Večina vojakov ni več razločevala med zvoki na bojišču. Ob vsaki malenkosti so se zdrznili. Bili so vedno vznemirjeni, napeti in zmedeni. Ti simptomi so se počasi spreminjali v 'čustveno izčrpanost': možje so postajali odsotni, brez energije, otopeli, psihično in fizično počasni, za vse jim je postajalo vseeno, niso mogli več razmišljati ali si zapomniti podrobnosti. $V$ takih okoliščinah se lahko pojavijo čudaška in nerazumljiva vedenja."

Izkušnje iz druge svetovne vojne se potrjujejo tudi v sodobnih vojnah. Marinski priročnik bojnega stresa FM 90-44 (2000) navaja iste simptome še danes (preglednica 1).

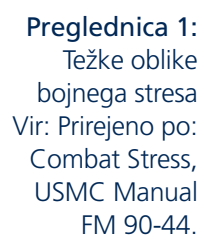

Preglednica 1:

\begin{tabular}{|l|l|}
\hline PODROČJE & ZNAKI \\
\hline \multirow{2}{*}{$\begin{array}{l}\text { vojak ne more biti pri miru, } \\
\text { ob nenadnem zvoku ali gibu se zdrzne/skloni/skrije, } \\
\text { govori neustavljivo, nejasno, jeclja ali sploh ne more govoriti, } \\
\text { trmoglavo ponavlja določene misli ali dejanja, } \\
\text { stoji odsotno, sključeno ali se pozibava, } \\
\text { doživlja hitre spremembe razpoloženja, } \\
\text { pestijo ga napadi besa, čustveni izbruhi, neustavljivo joka, } \\
\text { umika se iz družbe, } \\
\text { popolnoma izgubi zanimanje za dogodke okrog sebe, } \\
\text { "zmrzne« pred ognjem, } \\
\text { med bojem brezglavo teka, } \\
\text { ob nevarnosti mu postane vseeno, } \\
\text { vede se čudaško (nasilje, umori, samopoškodbe). }\end{array}$} \\
\hline Telesni znaki: & $\begin{array}{l}\text { ne more uporabljati dela telesa (roke, noge), čeprav ni opaziti fizične poškodbe, } \\
\text { neustavljivo se trese, } \\
\text { izgubi vid, sluh, tip, } \\
\text { je fizično izčrpan. }\end{array}$ \\
\hline $\begin{array}{l}\text { občutek popolne izčrpanosti, } \\
\text { občutek neobvladljivega strahu, žalosti ali groze, } \\
\text { nespečnost, pogoste in težke nočne more, } \\
\text { izguba spomina, } \\
\text { vidi ali sliši stvari, ki jih drugi ne (halucinira). }\end{array}$ \\
\hline
\end{tabular}


Maguen in drugi (2006) sklepajo, da so psihične motnje med vojaki rezultat zapletenega spleta dejavnikov. Na to, ali bo vojak psihično zbolel, vplivajo tako osebni dejavniki, značilnosti boja kot skupinsko in širše organizacijsko okolje.

V prispevku me zanima, ali so dognanja, opisana v omenjeni literaturi in torej omejena na angloameriški vzorec, prisotna tudi v vzorcu veteranov jugovzhodne Evrope.

Pri svojem delu izhajam iz medicinske paradigme stresa - da so ljudje biološko enaki in se temu ustrezno podobno odzivajo na stresne razmere, kar je nedvomno vojna. Tako je pričakovati, da se tako angloameriški kot avtorjev vzorec podobno odzivata na prisotnost nevarnosti, možnost poškodb, ran in smrti, tako na individualni kot skupinski ravni.

Zanimalo ga je, ali bo raziskava:

- pokazala podobno vedenje, kot sta ga opisala Marshall in Holmes;

- potrdila Grossmanov model psihološkega procesa ubijanja;

- potrdila Grosssmanov model dejavnikov, ki pospešujejo uboj;

- potrdila obstoj simptomov bojnega stresa, ki jih navajajo FM 8-51, FM 4-02.5 in FM 90-44.

\section{METODOLOGIJA RAZISKAVE}

Raziskavo sem začel izvajati leta 2003 in jo končal leta 2012. Najprej je bila usmerjena bolj na ugotavljanje prisotnosti in oblik bojnega stresa, pozneje, po letu 2009, pa se je razširila še na odnos do ubijanja in pojavnost dezintegracijskih procesov v bojnih enotah.

\subsection{Vzorec}

Vzorec je obsegal 120 veteranov, vsi so bili moški. S petdesetimi je bil opravljen poglobljen klinični intervju, s petdesetimi krajši intervju, informacije zadnjih dvajsetih veteranov pa so bile iz druge roke. O njihovih doživetjih so poročali svojci, prijatelji ali sovojaki.

Podatki niso bili lahko dostopni, saj veterani o vojni ne govorijo radi. Sogovornike sem večinoma pridobil z metodo snežne kepe (»snowballing«), pri kateri sogovornik, če oceni, da je raziskovalec zaupanja vreden sogovornik, priporoči raziskovalca tovarišu, s katerim sta bila skupaj v vojni.

Vzorec, po katerem so bili opravljeni klinični intervjuji (50 oseb), je bil sestavljen iz dveh podskupin. Prvo (35 oseb) so sestavljali veterani, ki so bili udeleženi v bližinskem boju, pri čemer jih je 15 navedlo, da so osebno odgovorni za uboj nasprotnika, 20 pa jih je smrt in rane sicer videlo, vendar ne vedo, če so tudi oni koga ubili. V drugi podskupini so veterani, ki niso bili v bližinskem boju. Šlo je za pripadnike zalednih enot in poveljstev. 
Za vzorec, s katerim so bili opravljeni krajši intervjuji (50 oseb), tako podrobna analiza ni bila narejena. Ta vzorec je bil priložnosten, večinoma je šlo za osebe, ki so same pristopile k meni in želele sporočiti svoje izkušnje iz vojn. Ker so pogovori potekali na javnem prostoru (šole, ulica), daljši in poglobljen razgovor ni bil mogoč. Omejen je bil na krajši opis kritičnih dogodkov. Večina teh intervjuvancev navaja, da je bila v bližinskem boju.

Od celotnega vzorca 120 oseb je bila večina Slovencev. Od tujcev so bili: 10 Američanov, 5 Hrvatov, 5 Bošnjakov, 3 Nemci, 2 Angleža in Izraelec. Vsi razen treh so bili pripadniki pehotnih enot. Od preostalih treh sta bila dva tankista, eden pa je bil pilot. Opisovali so izkušnje iz druge svetovne vojne, tako iz partizanskega boja v Sloveniji kot iz vidika nemških mobilizirancev, bojujočih se na vzhodni in zahodni fronti, vietnamske vojne, vojn na Balkanu v devetdesetih letih (boji v Sloveniji, na Hrvaškem in v Bosni in Hercegovini) ter vojn na Bližnjem vzhodu (Izrael, Irak, Afganistan).

\subsection{Metoda}

Metoda pridobivanja in analize podatkov je bila kvalitativna. Med intervjuji sem oblikoval zapiske samo, kadar sem ocenil, da zapisovanje intervjuvanca ne moti. Takih primerov je bilo manj kot 10 odstotkov. Večina jih je želela anonimnost in globljih razsežnosti doživljanja niso želeli opisovati, če so ocenili, da se pripravlja evidenca.

Klinični intervju je trajal najmanj eno uro in največ tri. Bil je polstrukturiran, pri čemer so bila vprašanja povezana z nekaterimi temami:

- opis bojne kariere in kritičnih dogodkov,

- opis doživljanja občutkov pred bojem, med njim in po njem,

- opis doživljanja smrti, ran, poškodb,

- opis mogočih stresnih reakcij med bojevanjem,

- opis mogočih dezintegracijskih procesov v enoti,

- opis psiholoških motenj, za katere menijo, da so posledica udeležbe v vojni.

Globina odgovorov je bila odvisna od odzivnosti in pripravljenosti intervjuvanca. Kadar sem ocenil, da se pri intervjuvancu pojavlja odpor - ta se je običajno pojavljal ob temah, kot so uboj ali lastne psihične motnje - sem to vprašanje zaključil in prešel na drugega.

Iz pridobljenih podatkov sem z metodo kodiranja ${ }^{1}$ razvil implicitno teorijo delovanja človeka in enote v boju, ki bo predstavljena v nadaljevanju.

\footnotetext{
Strauss in Corbin (1990) sta metodo opredelila kot postopek za organizacijo in interpretacijo pridobljenih podatkov, ki je sestavljen iz konceptualizacije in redukcije podatkov, oblikovanja kategorij in iskanja odnosov med njimi. Tovrstno iskanje odnosov, torej oblikovanje implicitne teorije, Jick (1979) imenuje triangulacija. Omenjeni avtor opozarja, da triangulacija obsega širok razpon, od preproste kvantifikacije kvalitativnih podatkov, pridobljenih znotraj ene metode, do holističnih (kvalitativnih, fenomenoloških) primerjav podatkov, pridobljenih z različnimi metodami.
} 


\section{REZULTATI}

Občutki pred začetkom vojne so različni in segajo od vznemirjenosti do tesnobe. Čez čas se človek na vojno prilagodi, vendar postaja vedno bolj previden, tudi prestrašen. Bolj kot je ogroženo njegovo življenje, hitreje se raztaplja njegov socialni čut in v skrajnih razmerah instinktivno skrbi samo še zase. Intervjuvanci navajajo primere, kako so se dogajali egoizem in pretepi že med napornimi usposabljanji, kako so v vojni brezglavo bežale cele enote ali kako je pred ognjem vsak, tako vojak kot poveljnik, iskal najboljši zaklon zgolj zase. Ti primeri niso pogosti. Zelo pogosto pa je kopanje tako globokih zaklonilnikov, da vojak ne vidi več ven, ali pa refleksno metanje po tleh ob vsakem zvoku, ki spominja na pok orožja ali hrup letalskega motorja.

Napovedovanje, kako bo vojak deloval v bojnih razmerah, je zelo težko. Intervjuvanci navajajo, da so pod ognjem odpovedovali tudi ljudje, za katere si ne bi nikoli mislili. Večina navaja občutek olajšanja, ko so videli, da so sposobni zdržati pritisk, čeprav obenem navajajo, da je ta pritisk zelo močan in zahteva veliko notranje moči. Verjetnost, da bo enota pritiske prvih bojev zdržala, se zveča s predhodno selekcijo, z dobrimi pripravami in izurjenostjo. Hladnokrvno vodenje je zelo pomembno.

V vojni človekova agresija naraste in lahko vodi tudi v skrajnosti, kot sta sadizem in uživanje v ubijanju. Teh skrajnih dejanj intervjuvanci sicer niso priznavali, so pa opisovali primere, ko so to delali drugi. Ti primeri niso pogosti, vendar sta me globina in brutalnost opisanih dejanj usmerila k vprašanju, kako lahko človek kaj takega drugemu sploh naredi. Najboljši odgovor je v Freudovi teoriji, po kateri ima vsak človek v sebi animalično jedro, ki je sestavljeno iz seksualnega (eros) in agresivnega impulza (tanatos). Dokler impulze nadzirajo privzgojena morala, norme in zakoni, so impulzi zapahnjeni v podzavesti. V vojni, ko je ubijanje celo pričakovano in zahtevano, pa omenjena protiutež izginja in slabša, kot je samokontrola in kontrola nadrejenih, močnejši bo izbruh prvinskih teženj.

Večina vojakov ne ubija iz užitka. Od vseh intervjuvancev je bil tak samo eden, vendar so me nekateri drugi poučili, da je takšnih primerov veliko več med vojaki, ki so jim pobili družine. Tega sicer nisem mogel preveriti, vendar dvomim, da gre pri njih res za ubijanje iz užitka. Verjetnejša razlaga je, da ubijajo iz globokega sovraštva. Večina ubija zato, da ohrani svoje življenje. »Če ne bi jaz njega«, je bil običajen odgovor, »bi on mene.« Naslednji sklop odgovorov nakazuje, da ubijajo tudi zaradi pritiska, bodisi nadrejenih bodisi sovojakov. Tako navajajo, da so delali tisto, kar jim je bilo ukazano ali pa so streljali zato, ker so streljali tudi vojaki okrog njih. »Če bi drugi bežali«, navaja eden izmed njih, »bi pa jaz tudi.« Pritiski nadrejenega gredo lahko v skrajnosti. Nekateri navajajo, da bi jih ubil sam, če ne bi streljali na nasprotnika.

Prvi uboji so najtežji, nato postaja vedno lažje. Veterani navajajo, da je najtežje ubiti človeka, ki ga vidiš; v enem primeru je intervjuvanec žrtev celo poznal in imel pred 
ubojem močno zavoro. Večina navaja občutek, da so bili prvi uboji kot slabe sanje in težko sestavijo sosledje dogodkov, če se jih sploh spomnijo. Prve uboje pogosto spremlja odsotnost spomina ali razmišljanja. Pozneje postajajo uboji hladnokrvnejši, na smrt in njeno zadajanje začnejo gledati z drugimi očmi. Intervjuvanci opisujejo, da se največkrat sploh ne ve, kdo je koga zadel. Da je bilo zgolj veliko streljanja in nekdo je pač padel.

V vojni začenjajo razum zamenjevati čustva. Tako se pojavijo občutja povezanosti z vojaki, s katerimi si delijo tegobe, ter občutja sovraštva do nasprotnika. To sovraštvo je še intenzivnejše, kadar je nasprotnik povzročil več škode bodisi njim bodisi njihovim tovarišem ali domačim. Sovražna čustva lahko vztrajajo tudi po koncu spopadov in, če ni vojna za vojaka postala preveč osebna, upadajo s časovno oddaljenostjo. Ko se vrača razum, se lahko pojavijo vprašanja o nesmiselnosti vojne in psihične motnje. Pogost je občutek, da so bili vojaki zavedeni ali prevarani in da so na njihov račun uspeli ljudje, ki so bili med vojno na varnem. O vojni raje ne razmišljajo in jo izrinejo iz zavesti.

Bojni stres je integralni del bojevanja. Veterani skoraj brez izjeme navajajo tresenje rok, zasoplost in močno bitje srca. Nekaterim se spremeni zaznava, bodisi da vročo kovino orožja zaznavajo kot hladno bodisi izgine njihov periferni vid (»tunelski vid«) ali pa se upočasni čas zaznavanja. Včasih ne morejo nadzirati delov svojega telesa, na primer spustiti prsta s sprožilca. Redko prihaja do resnih psihičnih motenj, kot so depersonalizacija (»vojak je vstal in se podal proti nasprotniku ... sploh ni vedel, kdo je, kaj dela, nič ...«), derealizacija, stupor (»kar ležal je negiben in sem ga moral brcniti v zadnjico, da je pritisnil na sprožilec«) ali paranoja.

Psihične motnje, ki se razvijejo po vojni, veterani prikrivajo. Ob površinskih razgovorih sicer navajajo, da jim vojna ni ostala $v$ dobrem spominu, vendar ne omenjajo, da bi imeli težje posledice. Globina psihičnih motenj se je razkrila, kadar je avtor z njimi navezal pristen in zaupljiv stik. V teh primerih so brazgotine razkrili skoraj vsi. Najblažje psihične motnje, ki jih je uspel zaslediti, so razdražljivost in motnje spanja, prestrašenost ob zvokih, ki spominjajo na zvok orožja, in napadi panike ob situacijah, ki spominjajo na vojno. Simptomi se zaostrujejo do depresij in v nekaj primerih tudi do resnih oblik PTSM, ki bi zahtevale klinično zdravljenje. Največje breme imajo tisti, ki so bili najbolj neposredno soočeni s smrtjo in uničevanjem, bodisi da so smrt opazovali ali so jo zadajali.

\section{REZULTATI RAZISKAVE}

Vedenje, ki ga navajajo veterani, kaže veliko podobnost z vedenjem, ki ga opisujeta Marshall in Holmes. V obeh primerih je opaziti širok spekter, ki sega od hladnokrvnega delovanja in prilagoditve na vojno do različnih oblik dezintegracije enot in posameznika. Rezultati kažejo, da so različne vrste vedenja podobne, kot sta jih opisala Marshall in Holmes. Kot kaže, ni razlik med občutji do vojne in delovanjem vojaka v boju med angloameriškim in vzorcem iz JV Evrope. 
Primerjava pričevanj veteranov z Grossmanovim modelom psihološkega procesa ubijanja kaže odstopanja. Avtor ugotavlja, da je spekter odzivov širši, kot navaja Grossman, in da ni nujno, da bo vojak ob uboju čutil vzhičenost, kakor da tudi ni nujno, da bo čutil obžalovanje. Drži, da se pojavi racionalizacija, vendar ni nujno, da je posledica notranjega konflikta med moralo in dejanjem, ki je z njo v nasprotju. Lahko gre za preprosto racionalno ugotovitev, da je vojna obdobje, v katerem moraš ubiti zato, da boš sam ostal živ, ali pa za identifikacijo z vlogo izvajalca, izpolnjevalca ukazov. Rezultati raziskave samo delno potrjujejo Grossmanov model psihološkega procesa ubijanja.

$\mathrm{Na}$ uboj resnično vplivajo pritiski nadrejenih in sovojakov. Vojak ubija z manj pomisleki, če je do nasprotnika sovražno nastrojen. Torej rezultati potrjujejo Grosssmanov model dejavnikov, ki pospešujejo uboj.

Rezultati prav tako potrjujejo obstoj simptomov bojnega stresa, ki jih navajajo FM 8-51, FM 4-02.5 ter FM 90-44. Veterani namreč navajajo več simptomov bojnega stresa, ki segajo od blažjih do težkih oblik, v takšnih pojavnih oblikah, kot jih navajajo ameriški priročniki o bojnem stresu.

Obseg ujemanj med angloameriškimi in avtorjevimi spoznanji nakazuje, da obstaja univerzalen model delovanja človeka in enot v vojni. Mogoč je zaključek, da gre za splošen odziv človeka na nevarnost, da gre za odziv človeškega organizma in skupine na bližino smrti. Vendar je pri generalizaciji teh spoznanj nujna previdnost.

Mnenja o univerzalnosti modelov delovanja človeka v vojni so deljena in preučevanje argumentov, ki jih navajajo določeni avtorji, razkrije tudi omejitve tako avtorjevih spoznanj kot modelov Marshalla, Holmesa in Grossmana.

Tako Gifford (2006, str. 16) poudarja, da enotna teorija psihologije boja ni mogoča, ker so izkušnje pehotnika drugačne kot izkušnje pilota, mornarja ali pripadnika zalednih enot. Različne izkušnje imajo celo znotraj enot namembnosti, ker se niso vsi srečali z isto obliko ali intenzivnostjo boja. Poleg teh dejavnikov na doživljanje boja vplivajo tudi kulturni in zgodovinski dejavniki, saj ljudje različnih kultur in zgodovinskih obdobij obravnavajo nasilje iz različnih perspektiv. Na izkušnje bojevnikov vpliva tudi stopnja razvitosti tehnologije: bojevanje z mečem prinaša drugačna doživetja kot izpostavljenost topniškemu napadu ali kemično-radiološki grožnji.

Z mogočimi razlikami med doživljanjem vojne glede na različne rodove se strinjam. Smiselno je, da se pilot ne bo srečeval s tako umazanimi oblikami bojevanja kot pehotnik in pričakovati je, da bo vojno res doživljal drugače. Tudi argument o kulturnih dejavnikih je smiseln, čeprav kaže, da je vzorec doživljanja pripadnikov zahodne civilizacije podoben. Res pa bi bilo zanimivo preveriti, če je podobno tudi pri pripadnikih vzhodne kulture. Menim, da bi razlike resnično našli, sploh pri posameznikih in skupinah, ki na smrt v vojni gledajo kot na čast in nagrado. 
Gifford ima pomisleke tudi o validnosti kvalitativnih raziskav, kot je tudi ta. Navaja, da so pričevanja običajno osebno obarvana in odražajo željo udeležencev, da bi se predstavili v pozitivni luči, zato jih ne moremo kvalificirati kot znanstveno opazovanje. In vendar, nadaljuje, se vojna ne pusti ujeti v znanstvene analize, zato so anekdote in literatura, ki so jih napisali udeleženci vojn in jih ima znanost na razpolago. Čeprav ima pomisleke, priznava tudi sam, da so kvalitativne raziskave kljub pomanjkljivostim še najboljši način za spoznavanje psihologije vojne, s čimer se strinjam tudi jaz. Težko je, da bi raziskovalec v vojni vihri sploh sodeloval, skoraj nemogoče pa bi bilo, da bi v njej vedenje opazoval nepristransko ali vojake preizkušal.

\section{Literatura}

1. Department of the Army, 2006. FM 4-02.51 (FM 8-51): Combat and Operational Stress Control. Vojska ZDA.

2. Department of the Navy, USMC, 2000. FM 90-44/6-22.5: Combat Stress. Vojska ZDA.

3. Gabriel, R., 1988. The Painful Field: The Psychiatric Dimension of Modern War. Greenwood press.

4. Gifford, R., 2006. Psychological aspects of combat. V T. Britt, Cart Castro in Amy Adler, ur. Military performance vol. 1. Westport: Praeger, 2006, str. 15-19.

5. Grossman, D., 2009. On Killing. New York: Back Bay Books.

6. Grossman, D. in Christensen, L., 2004. On Combat: The Psychology and Physiology of Deadly Conflict in War and in Peace. PPCT Research Publications.

7. Holmes, R., 1985. Acts of War-The Behavior of Men in Battle. New York: Free Press.

8. Jazbec, G., 2010. Zapiski iz intervjujev z veterani. Lastna zbirka.

9. Jazbec, G., 2009. Bojni stres. Interno učno gradivo SV.

10. Jazbec G., 2012. Vojna. Trbovlje: samozaložba.

11. Jick, T., 1979. Mixing Qualitative and Quantitative Methods: Triangulation in Action. Administrative Science Quarterly 24 (4), str. 602-611.

12. Maguen in dr., 2006. Predictors and prevalence of posttraumatic stress disorder among military veterans. V T. Britt, Cart Castro in Amy Adler, ur. Operational stress, vol 2. Westport: Praeger, 2006, str. 142-143.

13. Marlowe, D., 2000. Psychological and Psychosocial Consequences of Combat and Deployment with Special Emphasis on the Gulf War. RAND.

14. Marshall, S., 2000. Man Against Fire: The Problem of Battle Command. Norman: University of Oklahoma Press.

15. Riddle, M. S., Sanders, John W., Jones, James J., in Webb, Schuyler C., 2006. „Selfreported Combat Stress Among Troops Deployed to Iraq and Afghanistan: an Epidemiologocal Study«. Bruselj: RTO-MP-HFM-134.

16. Strauss, A. in Corbin, J., 1990. Basics of Qualitative Research: Techniques and Procedures for Developing Grounded Theory. Thousand Oaks: Sage. 